\title{
Enhancing Performance of Mwasalat Misr Company in Greater Cairo-Egypt during COVID-19 Pandemic
}

\author{
Ashraf Elsafty ${ }^{1}, \&$ Mohamed Shaarawy ${ }^{2}$ \\ ${ }^{1}$ DBA., MBA., BSc., Adjunct Assistant Professor, ESLSCA University, Egypt \\ ${ }^{2}$ MBA candidate, Mwasalat Misr, HR Director, Cairo Egypt \\ Correspondence: Ashraf Elsafty, Adjunct Assistant Professor, Eslsca University, Egypt. ORCID ID: \\ https://orcid.org/0000-0002-9377-7286. E-mail: ashraf.elsafty@eslsca.edu.eg; ashraf@ashrafelsafty.com \\ Received: January 2, 2022 \\ Accepted: February 2, 2022 \\ Online Published: February 14, 2022 \\ doi:10.5539/ibr.v15n3p31 \\ URL: https://doi.org/10.5539/ibr.v15n3p31
}

\begin{abstract}
This research study explores human resource management decisions, management roles, and how they can have a significant and unique impact on the performance of the Mwasalat Misr organization. The survey adopted a qualitative survey design using a sequential narrative approach using unstructured interviews and a stakeholder analysis approach using open-question questionnaires. The research focuses on how to advance the public transport industry by advancing the relationship between HRM and organizational performance. Some of the key unresolved issues that require further research and help industry management investigate these issues and build a more cumulative body of knowledge that has important implications for theory and practice. Suggestions. The study concludes that four factors influence performance: personnel decisions, management roles, employee satisfaction, and cultural and organizational behavior. The COVID 19 pandemic has been found to serve as a parameter between the completed variable and the company's performance.
\end{abstract}

Keywords: performance, human resources, public transportation, management ambiguity, COVID-19

\section{Introduction}

\subsection{Introduce the Problem}

Beginning of 2011 as a Joint-stock company with the name of Egyptian Advanced company for Public Transportation, in 2014 having a smart minibus integrated route with the metro known by Misr BUS, in 2015 restructuring and evaluation with the new strategic partner the European Bank, and finally the accusation of 70\% of the shares by Emirates National Group and change the name to be Mwasalat Misr in 2016. Why did the company choose The Public Transport solution? Why in Greater Cairo? Greater Cairo is one of the busiest mega-cities in the world. It is estimated that 25 million rides with all transport modes take place daily, if you take into account, people who commute in and out of Greater Cairo every day, the number is estimated to go up to 30 million. Note that Uber has announced that they conduct 14 million rides per day across their global coverage in more than 230 cities.

Because one of the main root causes of Cairo traffic is that many car owners rarely if ever consider using public transport even if there is a variety of available transport options in Cairo: CTA bus. Mini-Bus, Micro Bus, Metro even Tok-Tok and Uber taxi.

According to (Elsafty, 2020) the Nine Elements Framework Model can cover all sides around our problem we can understand our research problem through this model which explores the kind of research organization, management level, business functions, internal \& External environmental factors, geographical location and industry field we can explore all of these elements within the time frame (Elsafty, A., Elsayed, \& Shaaban, 2020; Elsafty A., \& AlNawaly, 2020; Elsafty A., \& Ragheb, 2020; Elsafty, A., \& Abadir \& Sharawy, 2020; Elsafty, A., Elbouseery, I., \& Sharawy, A., 2020; Elsafty, A., \& Tahon, A., 2021; Elsafty, A., \& Elzeftawy, A., 2021). 


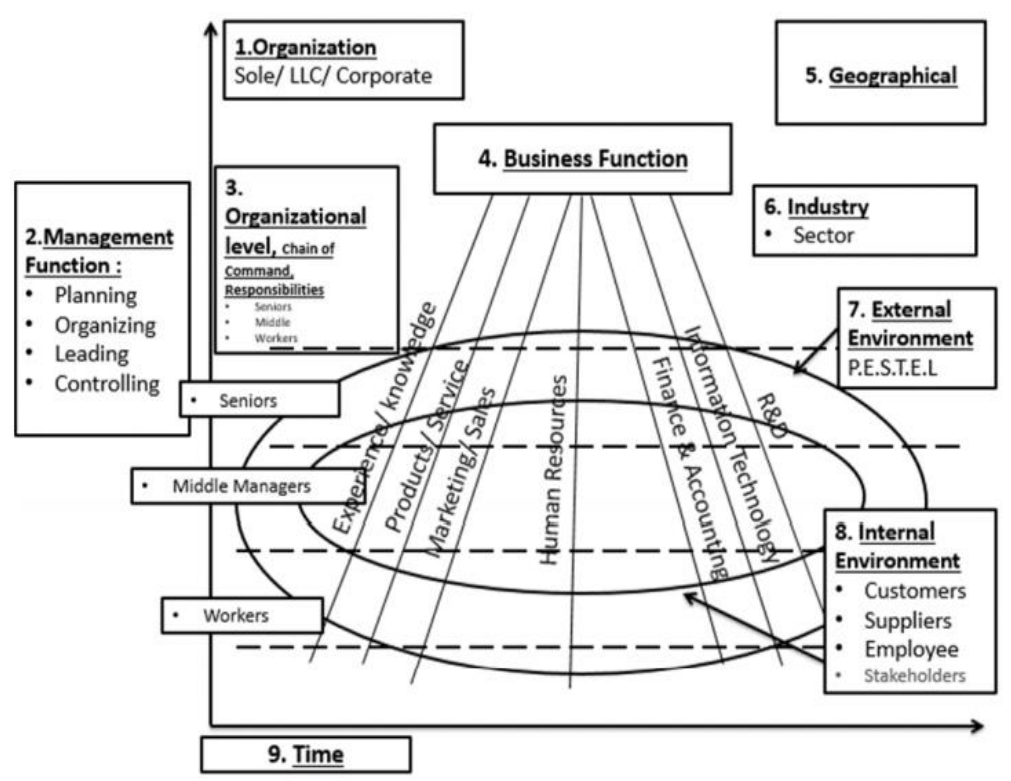

Figure 1. Business Anatomy the 9 Elements Model Proposed by Elsafty (2018)

As a result, the article used the Nine Elements Model/Framework (Elsafty, 2018, 2019, 2020) to analyze and correctly identify the problem of this article which focuses on going into the depth of organizations and analyzing the external and internal environment, and thanks to this, we were able to identify the impact on company performance within the public transport industry.

Focusing on The public transport sector, because it covers more than $80 \%$ of rides, these different modes are regulated by different governmental bodies ( Cairo Transportation Authority CTA, Ministry of Housing, New Urban Communities Authority NUCA, Governorates, Etc.) who rarely communicate and align with each other, this causes many problems regarding service quality and reliability. As a result, the available transportation options can be segregated into two groups. A high-end group that is available to a limited portion of the population (private cars, Uber, etc.), and a lower-end public transport group that offers unfavorable experiences (Minibus, Microbus, etc.)

If we look at the available options and rate them on different criteria such as cost, quality, convenience, and social perception, we will realize that the "perfect" mode of transport does not exist. There was a gap in the market that needed to be filled. There had to be a public transport service that is affordable for the middle class and offers a premium experience at the same time. Therefore, Mwasalat Misr has decided to penetrate the local market as an urban mobility solution provider for the middle class in greater Cairo. But to do this, the company must be sure of the quality of the service, therefore, to have this type of service with high technology, we need very qualified and adaptable staff to ensure this quality. This is why the role of human resources is crucial to improving performance.

The company is aiming to the implementation of a public transport network by international standards for sustainable urban transport, aims also at filling the existing gap in the market by providing premium, reliable services at affordable prices. Most importantly, the company aim at destigmatizing public transport.

Mwasalat Misr is the first and only private urban mobility provider in Cairo to launch the smart city bus by the standards of UITP (International Union for Public Transport), the buses are accessible to wheelchairs, supports people with visual impairment through stop audio announcements as well as braille compatible stop buttons. It is also accessible for people with hearing disabilities through digital signage and PIS (Passenger Information System) the fleet is equipped with USB charging ports, CCTV, and onboard Wi-Fi for added convenience, also equipped for electronic fare payment through smart cards. It's not very common for founding drivers to be able to use this high-tech, so selection and training is the only way and one of the cultural changes we're working on. The launch with a service like Mwasalati cards which is an electronic wallet that customers can use to pay on the bus, it is not a subscription card, it is similar to the card you would find in pioneering cities, such as Dubai, London, or Paris, this card works with the same technology of Cairo Metro and we are currently working on full 
integration, our customer can top-up their Mwasalati cards through more than 80,000 Points of Sale for Fawry. It is not very common also in Egypt to use and trust this type of wallet, so culture change is also needed for all the clients, so this is our role as innovators.

The smart buses are fully integrated with Google Maps (just like Europe), any phone user can plan their trip, know the timetable, and track the bus's location on the map. No booking or app download is required to enhance the reliability of these services. Like any European city, the company co-created a schematic map for the bus lines network, which is integrated with the Cairo Metro network, every bus line operates intersects with the Cairo Metro network at least at one Metro station.

The company biggest pride comes from the service reliability, the main KPI for the company is schedule adherence, the company is in a journey to reach absolute accordance with the timetables, currently, the schedule execution accuracy is around 3 minutes, and the company aims to close 2020 under 1 minute of variance although it uses an Artificial Intelligence engine to calculate the estimated time of arrival for each bus stop and develop schedules accordingly.

This kind of service will change the way of life not only the culture of the clients, but they also don't have to wait for the bus, finally, they can plan their trips and it will help people to organize their daily plan, so with this reliability, no more delays and maybe one day Egyptians will arrive on time!

Talking about the challenges and change culture must not forget one of the challenges facing the company like all organizations this year is the pandemic COVID-19, with the curfew and also the demand for social distancing which has significantly reduced revenues and slowed down the company's development. To succeed and put the project at risk, it was necessary to react quickly to the rapid changes in habits and behavior with the new rules of the Ministry of Health, to protect employees and customers, compulsory mask, cleaning and disinfection of buses, social distancing and this was managed and overseen by the human resources department, with the challenge of keeping employee motivation and retention with zero budget. To be able to achieve this kind of result the company is obliged to change its own culture and the role of human resources and too important. The current network covers Greater Cairo from the 10th of Ramadan city in the East to the 6th of October in the west, the company aim at providing seamlessly interconnected trips for all Cairo residents. To cover this Geographical network, we have 4 Garage Katamey, Mostorod, Zayed, and October with a large network that covered all of greater Cairo from Al Asher, Al Shrouk, Al Obour, New Cairo, Cairo, Giza, Zayed, and October to interconnect everything with the network of metro and in a few months, we'll be covering The New Administrative Capital, with such a large network, we had to work with an organic structure, which is why we have a matrix organization structures. our company group consists of 5 companies,

Mwasalat Misr the holding company placed under it 1- CPT: large buses.2- HPT: minibuses.

3- Easy Mobility: IT. 4- Transmedia: Media.

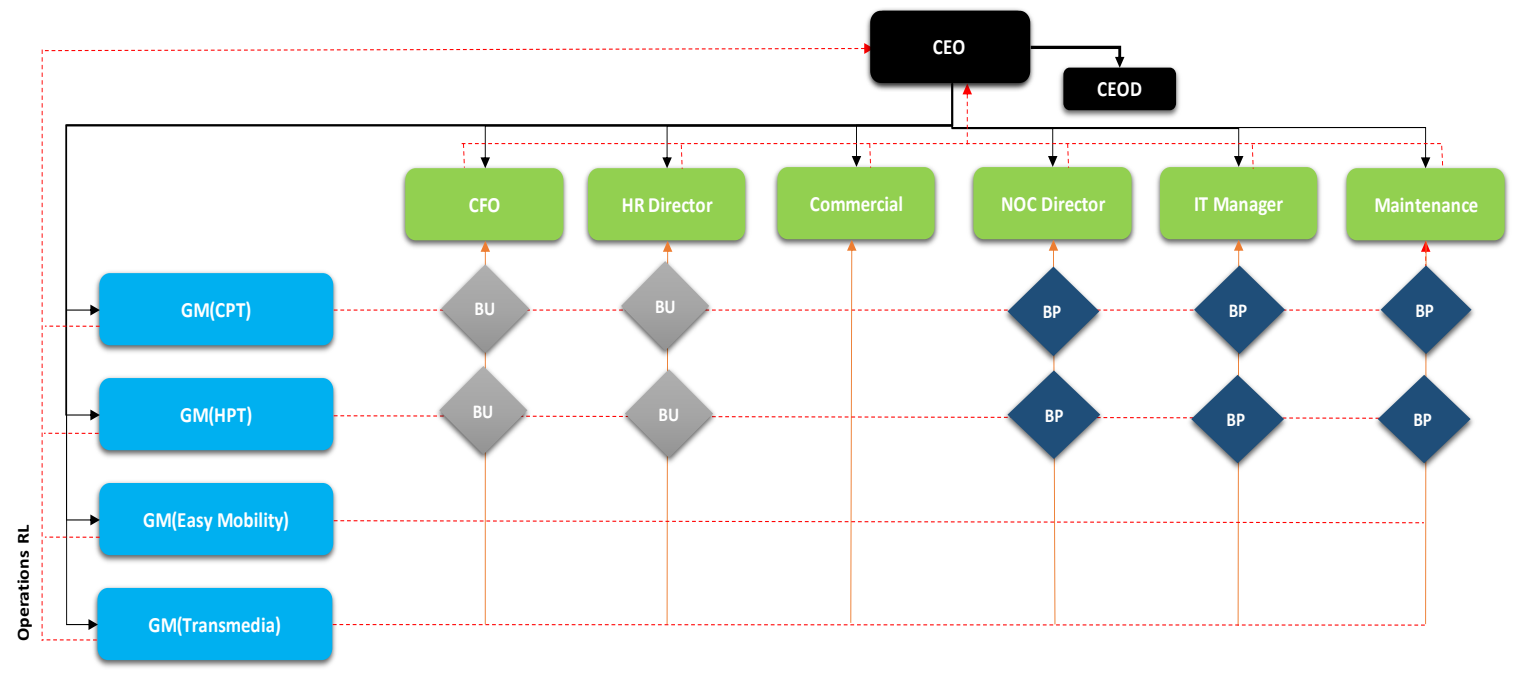

Figure 2. the matrix organization structures of Mwasalat Misr Group 
The industry manager considers that the performance of employees especially of the drivers is not predictable, so the majority of companies made a simple module of wages related to income in percentage to avoid solving the main problem (the performance). This has led the drivers to target only a Hugh number of customers regardless of the given quality, and that's why the middle class don't just use public transport only if it has no other choice.

After making Individual unstructured interviews with the CEOs of the 5 biggest companies we can deduct the follows; the public transport companies do not have an HR department, only personnel. It sees this as a cost and not an added value, as the directors of its companies said in this sentence "the only motive of drivers is money". Therefore, we have real problems in the Egyptian market especially in Cairo to find trained and professional drivers.

But the problem is not just the drivers, we have the same ignorance in all the technical support regarding public transport even the maintenance engineering, its kind of impossible to find a good caliber in the field of public transportation. As all the companies do not care about motivation, job environment, safety, or even the way to treat employees, this culture and this organizational behavior need to be improved to ensure a better quality of calibers in this field, which is why I will try to highlight the role of HR and the impact on the performance.

Then conducting different Individual unstructured interviews with some of the employees, the different opinions of the employees show that they need a minimum feeling of stability at work, having a good working environment, with some limited basic and simple safety and security, not just having the incentive on the number of clients to define their monthly salary, a minimum basic wage if they have reasons for not working can have a minimum income in case of illness and this kind of absence, so for the situation of COVID-19 companies do not have any liabilities or commitments to employees.

This causes real instability in the market and the good caliber leaves the field of public transport and changes the industry, they go to work with schools buses or tourism and transport of employees, etc.., to finally have a stable salary without a daily fight with the problems on the road which cause a lot of accidents and risks for them because they operate without a contract once they occur a problem, they have no rights, results of that bad work environment only employees who can fight and struggle to have their place remain in this industry so not the best calibers, of course, this decreases the quality all the situation because of the inexistent of HR role. with all this nobody sees the interest of the customers and the quality of their service offered.

This explains why middle-class customers hardly ever use public transport, only people who cannot have other means of transport will be almost forced to use public transport, therefore, to change this culture from employees until customers we need to have a different role for HR in this industry, that we are trying to do it in Mwasalat Misr by changing and enhancing the performance of employees so by the end to improve the company's performance. We have already begun to change this culture in the company, and we are aiming to change the whole industry culture.

As a participant observation and the data available in companies with the special help of the customer service department and the specific customers' needs and complaints data, research can deduce that customers explain the performance they expect from companies and employees; they need safety, reliability, and good communication with them, as we can see all those needs related directly with the employees' performance, the great challenge, in particular in terms of reliability and driver behavior but also in the way of driving and this almost the reason for the no usage of many customers to the public transport service in a daily basis only when they have force-majeure, they usually take their cars or taxis, also some customers have the difficulties in using new technology. Working on customer culture through the quality of our interlocutors and employees. To achieve customer satisfaction, it is a must to work on the quality of services provided to the customers through our employees, which will ultimately increase performance, we need to mention how the role of HR is crucial to enhance the organization's performance.

All this lead to understanding that this is an industry with a real challenge to offer a satisfactory quality of service to the Egyptian middle class, what can we do to improve the performance of the Mwasalat Misr company, and how to increase the performance of Mwasalat Misr company and the reflection on the industry culture shift and customers' behaviors? Is there a relation between Human resources decisions, Management role, Culture \& Organizational behavior on the organization's performance? the influence of the Covid 19 pandemic on organization performance?

Therefore, the good decisions of Human resources improve and sustain organizational performance though the good management style will increase the performance of the organization, the culture, and the organization behavior will help to improve the service, but the pandemic will be a real challenge and maybe will decrease the performance for a while. 
This research will answer the question of how with the challenge of the Covid 19 pandemic could we enhance the performance of Mwasalat Misr and the public transfers sector in Greater Cairo?

\section{Literature Review}

\subsection{The Impact of HR Decisions on Organizational Performance}

Why do we always describe very important human resource decisions and directly influence the performance of organizations? It is for this reason that we will further develop the importance of the relationship between human resources and performance; with the dynamic economic situation, all the organizations try to improve their performances by reducing expenses, by improving the quality, or innovating the products.

This research is focusing on decisions related to human resources and how these decisions play a role in the performance of organizations, it is how HR directors and managements have with their HR system a chance to improve the performance of their organization. How can HR decisions influence performance? Simply: these decisions must either improve efficiency or help increase income.

Most managements see human resources as work and function as an expense and they are always trying to decrease these expenses, it is an opportunity to decrease expenses to increase income. (efficiency gains) especially when the salary budget is in many organizations the highest, Reducing the number of employees, therefore, remains a strategy to reduce expenses and improve efficiency and therefore performance as of our industries managers sees exactly but here you have to be very careful, do your decisions create values, or only cost reductions? It is, therefore, necessary here to make the difference between a reduction of the workforce to save money and an effective HR restructuring which the company needs to be up to date with the strategies of the organization and to not reduce the quality of services, it is for these types of decisions that the HR must intervene and not the financiers or the employers.

The roles of human resources managers must directly contribute to the implementation of the operational strategy. The importance of human resources as a strategic lever has become mandatory, this role weighs heavily on the psychology, economics, finance, and strategy of an organization (BECKER \& Barry GERHART, August 1996)

However, a potential benefit in this regard is that most of the articles directly examine the impact of HR decisions on performance results that have clear meaning and relevance to managers, such as inventory performance, productivity, profits, quality, and organization survival. Additionally, this research suggests that HR can go beyond their organizational role to become a strategic partner in most organizations (BECKER \& Barry GERHART, August 1996)

Human resource strategies can be a particularly important source of sustainable competitive advantage.

The concept of the HR system as a strategic asset has implications for both the characteristics and the effects of such a system. Strategic assets are "the set of resources and capacities that are difficult to exchange and to imitate, rare, appropriate and specialized which give a competitive advantage to the company" Unlike investments in the capital, economy, or patents, a properly developed HR system is an "invisible asset" that creates value when it is so integrated into an organization's operational systems that improve performance and business capabilities (Gregorio Martion de Castro, Lopez-Saez, \& Alama-Salazar, 2005)

In our case we can simply by having such a system with an adapted HR decision a real role to change the culture of the entire industry, recruiting decisions in HR practices with its different internal or external, we must also note that it is not only the fact of being good at doing the job, but for example the potential disadvantages of not letting human resources choose and varying employees after a time the employees of the organizations can become somewhat homogeneous because managers tend to hire like them and this process grows stronger, while this homogeneity can work well in an organization, but any change in this organization can result in a real struggling to adapt due to its lack of diverse skills. This formulation suggests one of the elements of a successful HR system, in changing circumstances, must be flexibility. Although flexibility is not a feature of most organizational systems, if strategic HR systems are truly aligned with business issues and operational initiatives, and this perspective is built into the system and organization, all stakeholders will anticipate system change as they see the issues of the company evolve.

\subsection{Performance Effectiveness and Human Resource Decisions}

Business efficiency metrics have natural and clear parameters (e.g. shareholder performance, profits, productivity) that are not the same for HR, the importance of HR metrics in any business; that we can measure performance that often differs significantly between different business units and different size also nature of each organization and the performance of financial results, but there are usually other significant metrics such as cycle 
time, customer satisfaction, etc. which are directly linked with HR decisions and conceptually linked to employee performance and increase business performance (BECKER \& Barry GERHART, August 1996)

The strategic management perspective must develop the relationship between the HR system performance and the financial results of the organization, especially when we are speaking about drivers who are the origins of the revenues in the public transportation companies, Unless and until one can develop and test more comprehensive model structures it will be difficult to rule out alternative causal models that explain the observed associations between HR systems and company performance.

looked at both the company level performance results and the HR performance results, the best we can do is look at the group of studies and say that HR was related to performance at both at the enterprise and establishment level. The fact that none of the studies used results at the business unit level may indicate the difficulty of measuring performance. There is a clear need to fill this gap at the business unit level and pay attention not only to traditional financial results, but also to intermediate and process-related results, criteria that indicate how financial results are achieved, and by whom? and who selects the calibers who help to have those results? and reflect the human factor in the decisions that achieve performance? So, if we applied this on our case we need to improve the employee's performance without depending only on the revenues but also the customers' satisfaction and the retention of the customers and some other important factors, to give an example here, companies that have profit share:

Does profit-sharing increase profit? or is it because the company has high profit must have a profit share? Do the employees of the companies who benefit from this system have a different attitude? have they helped get more profit from employees who don't have this benefit? Do these differences also translate into different customer levels, satisfaction, productivity, etc.?

So perhaps the effect of HR decisions on business performance, HR systems only have a systematic impact on performance when they are integrated into the management infrastructure of a business and help solve real business issues such as product development cycle times, customers. service, and so on.

The particular form of these issues and, more importantly, the proper alignment of the HR with business-specific is more than only leadership or cost differentiation business strategies, a properly aligned HR system would represent a core capability and become a form of organizational capital, every business should have a distinctive HR system this is the core competency for that particular organization. As long as the proper alignment of an HR system with the particular business issues of a particular organization is complex, indeed it needs a very strong management decision and also depends on the ability of each company to align its HR system with its business challenges and operational initiatives, this interpretation suggests the need to work harder to fit between the different functions. It may also involve a different research objective. This research has changed the game of recurring executive compensation issues. The studies included here support the strategic impact of HR on key performance outcomes, and I believe this type of research will accelerate the development of a cumulative body of knowledge that will provide new strategic leverage for senior management. What are the political implications of this work? The most fundamental implication is that the choice of HR systems can have a significant effect on the performance of an organization.

\subsection{Performance Management \& Culture}

Performance management is a continuous process of "identifying. Measuring and developing the performance of individuals and teams and aligning performance with the strategic goals of the organization" (Aguinis, Harry, \& Ryan, 2012). We have mains five performance management phases that must be implemented to enhance any company's performance, but we always forget the influence of the culture to be sure that will give the attended results. So, at first, the job descriptions need to be very specific and congruence with the organizational goals, and depending on the organizational culture you need to choose between creating and maintaining a job description highly specific and clear or encouraging employees to participate in the creation of the job description.

The training and development are recommended to help on the organization goals and to enhance the performance also need to provide adequate training to all participants in the performance management process including managers and employees, this is an important determinant of management effectiveness, also how to provide the training program according to the corresponding culture to be sure of the result.

Example: Focus on the provision of individual training programs in cultures more individualistic, highly standardized, and structured. Measuring the performance in a good management system we need to measure with the most fairness to major the result and the behaviors at the employee also performance management systems 
include behavioral and outcome measures regarding individual and team performance.

Providing performance feedback is essential to enable employees to improve performance in the future.

Providing positive feedback on how employees are using their strengths to be successful and asking them to maintain or further improve their performance by focusing on their goals, managers responsible for providing feedback must respect the subtlety of each employee depending on their different culture to not having a negative impact.

Finally, depending also on the culture we must choose the reward type that helps on the organization goals and to enhance the performance and we must avoid the unfairness of rewards through individual performance, provide them with a very clear and detailed description of the types of behaviors, the collective and individual results that the organization expects to earn the rewards, all rewards must have the meaning of receiving them, they must be important in the eyes of employees, receiving or receiving such rewards must be important to them (Aguinis, Harry, \& Ryan, 2012)

In the following table, we can see a clear example to respect cultural dimensions in implementing performance management.

\begin{tabular}{|c|c|c|c|}
\hline $\begin{array}{l}\text { performance } \\
\text { management } \\
\text { universals }\end{array}$ & $\begin{array}{l}\text { Illustrative } \\
\text { Context }\end{array}$ & Illustrative Countries & Recommendations for practice \\
\hline \multirow{2}{*}{$\begin{array}{lr}\text { 1-Congruence } & \\
\text { between } & \text { job } \\
\text { descriptions and } \\
\text { organizational goals }\end{array}$} & High uncertainty avoidance & $\begin{array}{l}\text { Japan, Germany, France, } \\
\text { Mexico, South Korea }\end{array}$ & $\begin{array}{l}\text { Create and maintain job } \\
\text { descriptions that are highly specific } \\
\text { and clear }\end{array}$ \\
\hline & Low power distance & Austria, Israel, Denmark & $\begin{array}{l}\text { Encourage employees to be active } \\
\text { participants in the process of } \\
\text { creating job descriptions }\end{array}$ \\
\hline \multirow{4}{*}{$\begin{array}{l}\text {-Training } \\
\text { regarding } \\
\text { performance } \\
\text { management } \\
\end{array}$} & $\begin{array}{l}\text { High individualism (ie., low } \\
\text { collectivism) }\end{array}$ & $\begin{array}{l}\text { Denmark, New Zealand, } \\
\text { Ireland, Italy, France }\end{array}$ & Provide individual-based training \\
\hline & High uncertainty avoidance & $\begin{array}{l}\text { Greece, Belgium, Poland, } \\
\text { Peru, Hungary }\end{array}$ & $\begin{array}{l}\text { Provide highly standardized and } \\
\text { structured on- and off-the-job } \\
\text { training }\end{array}$ \\
\hline & $\begin{array}{l}\text { High femininity (i.e., low } \\
\text { masculinity) }\end{array}$ & $\begin{array}{l}\text { Sweden, } \\
\text { Netherlands, Costa Rica, } \\
\text { Thailand }\end{array}$ & $\begin{array}{l}\text { Provide training programs that } \\
\text { contain opportunities for } \\
\text { interpersonal interactions among } \\
\text { training participants }\end{array}$ \\
\hline & Low power distance & $\begin{array}{l}\text { Finland, Norway, Germany, } \\
\text { Sweden }\end{array}$ & $\begin{array}{l}\text { provide training programs that } \\
\text { promote active trainee participation }\end{array}$ \\
\hline \multirow{2}{*}{$\begin{array}{l}\text { 3-Measurement of } \\
\text { performance based } \\
\text { on routes and } \\
\text { behaviors at the } \\
\text { individual and } \\
\text { collective levels }\end{array}$} & $\begin{array}{lcc}\text { High fatalism } \\
\text { self-determinism) }\end{array}$ (i.e., low & India, Russia, and Mexico & $\begin{array}{l}\text { Emphasize behaviors over results } \\
\text { (but measure both) }\end{array}$ \\
\hline & $\begin{array}{l}\text { High individualism (i.e., low } \\
\text { collectivism) }\end{array}$ & $\begin{array}{l}\text { United States, Australia, } \\
\text { United Kingdom, Netherlands }\end{array}$ & $\begin{array}{l}\text { Emphasis individual over } \\
\text { collective (i.e., team, unit, } \\
\text { department, } \\
\text { performance (but measure both) }\end{array}$ \\
\hline \multirow{2}{*}{$\begin{array}{l}\text { 4-Delivering } \\
\text { performance } \\
\text { feedback using a } \\
\text { strengths-based } \\
\text { approach }\end{array}$} & High power distance & $\begin{array}{l}\text { Malaysia, Guatemala, } \\
\text { Mexico, China, Iraq. }\end{array}$ & $\begin{array}{l}\text { Encourage supervisors to deliver } \\
\text { performance feedback (rather than } \\
\text { peers or subordinates) }\end{array}$ \\
\hline & $\begin{array}{l}\text { High collectivism (ie., low } \\
\text { individualism) }\end{array}$ & $\begin{array}{l}\text { Guatemala, South Korea, } \\
\text { Singapore, China }\end{array}$ & $\begin{array}{l}\text { Use non-confrontational and } \\
\text { indirect language, preferably in } \\
\text { informal settings }\end{array}$ \\
\hline \multirow[t]{2}{*}{$\begin{array}{l}\text { 5-Allocating } \\
\text { rewards that are } \\
\text { meaningful }\end{array}$} & $\begin{array}{l}\text { High collectivism (i.e., low } \\
\text { individualism) }\end{array}$ & $\begin{array}{l}\text { Ecuador, Taiwan, Sierra } \\
\text { Leone, Nigeria }\end{array}$ & $\begin{array}{l}\text { Avoid large Levels of inequity in } \\
\text { rewards } \\
\text { performers Holding a similar } \\
\text { position in the organizational } \\
\text { hierarchy }\end{array}$ \\
\hline & High uncertainty avoidance & $\begin{array}{l}\text { Argentina, Portugal, Turkey, } \\
\text { Uruguay }\end{array}$ & $\begin{array}{l}\text { Provide a very clear and detailed } \\
\text { description of what specific types } \\
\text { of intangible and tangible rewards }\end{array}$ \\
\hline
\end{tabular}

Figure 3. (Table1) Summary of best practice recommendation son how to consider performance management universal sand cultural dimensions in implementing performance management (Aguinis, Harry, \& Ryan, 2012) 


\subsection{Job Satisfactions and Performance \& Organizational Behavior}

In discussions of organizational success, managers often say that employee morale is one of the critical success factors. Even Napoleon said: "The effectiveness of the army depends on his size, training, experience, and morale, and morale is worth more than any other factor together." Focusing on recent times we could generally say that managers want to have satisfied employees who feel good about their workplace; they prefer working with people who have a positive outlook on work. Workers who have a high level of job satisfaction generally love their jobs; they feel justice in an environment in which they work and feel that their work gives them positive characteristics such as variety, challenge, good pay and security, autonomy, pleasant colleagues, etc. Happy workers at work will even devote private time to their professional activities, they will be creative and engaged, they will look for a way to overcome any obstacle that may exist in carrying out their work, and they will help their colleagues and superiors.

These workers will have performance, and businesses with these types of workers will be successful. But is It's always like that? Is job satisfaction such a crucial factor in organizational behavior? The general answer to this question is "yes". However, it is important to stress that the relationship between job satisfaction and organizational performance or organizational success is far from simple and straightforward, Organizational performance is not just individual performance (Bakotic, 2016).

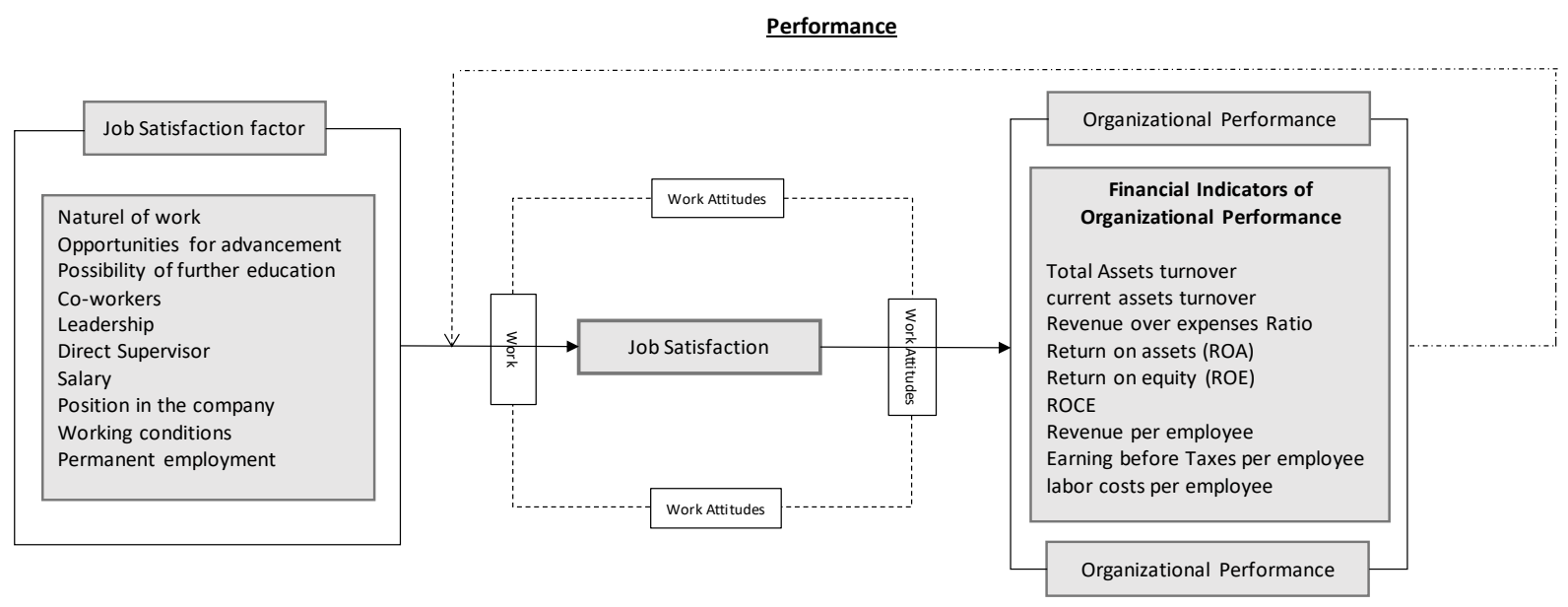

Figure 4. Conceptual model of the relationship between job satisfaction and organizational performance

Source: created by the author (Bakotic, 2016)

Research results from numerous studies suggest the existence of a positive correlation between job satisfaction and individual performance and also address the relationship between job satisfaction and organizational performance (Chan \& Steiner T. L., 2000) (Chandrasekar, 2011) (Ostroff, 1992)

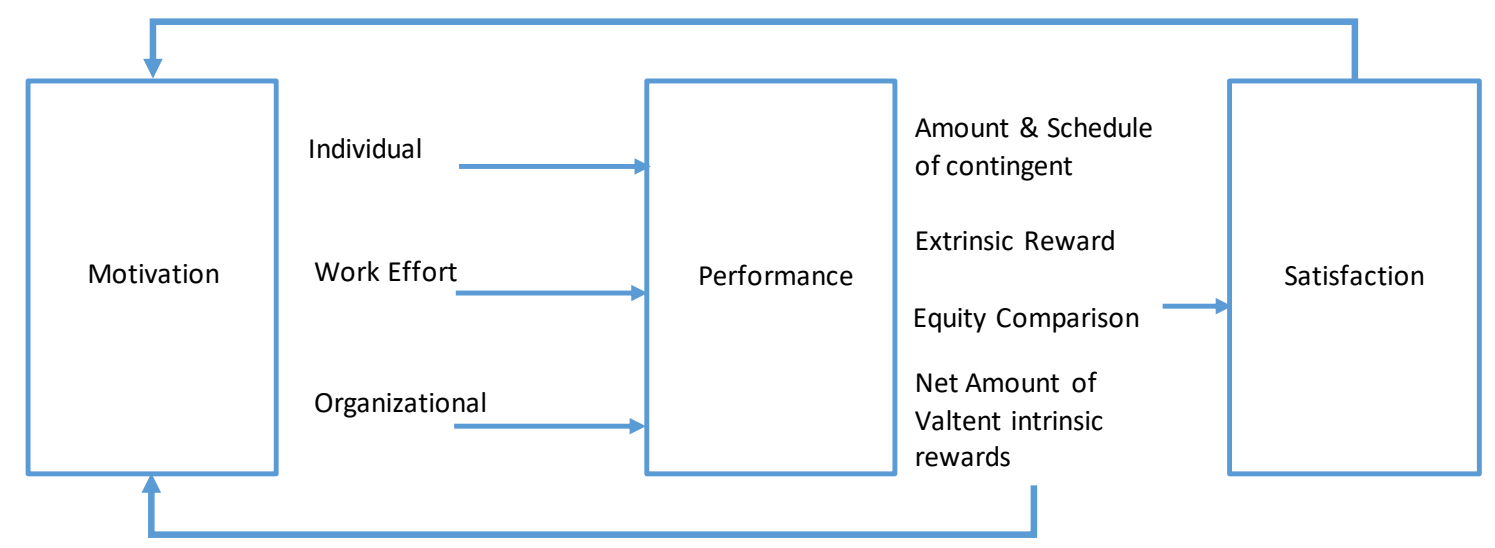

Figure 5. An integrated model of individual motivation to work (Jalagat, 2016) 
The essential elements for the success of any organization are employees are the best assets for the organization to function well, we need the interaction of people to check the success of the organization, the basic building blocks of an organization are people and their relationships with each other others. Borrowing from this point of view, employees should not be isolated but should be encouraged by management to work together, employee efforts will pave the way for the performance and success of the organization, working together for favorable results whether it is the capacity of the team or the organizational level. Additionally, given the statement that "two heads are better than one" working together as a team with a goal in mind is likely to achieve a higher level of success over some time and to be an effective team, this should level of performance of tasks, that is, achieve all performance objectives of the organization as a team.

\section{5 the Australian Experience an Alternative to Simulators and Computer-Assisted Training}

Inspired by the article when technology improves driver training the recruitment, training, management, and retention of drivers are essential processes in any public transport company.

Drivers are the foundation of safety and accident prevention. They are directly responsible for the safety of passengers and that of other drivers and road users. Training in the progress of drivers is essential to reinforce good practices conduct and ensure that they comply with standards of competence and operating procedures. Many smart technologies applied to transport can increase the safety, efficiency, and reliability of public transport systems (Ian Haynes, 2005).

All the review that I have found informs the relationship between the different variables and the phenomena, especially in the industry not only in Egypt but also in a similar situation all over the world. and that confirms more or less my claims quoted at the beginning as followed.

\section{Methodology}

The study used a qualitative research design, using sequential order of narrative approach using unstructured interviews then stakeholders' analysis approach using an open-ended questionnaire. All supported and compared to the observation, and reviews of records and documents of the company numeric information, as the main objective of this research, is to determine after reading the literature review the relations and effects between the variable, depending on the models and dispersed variables, this data will be analyzed using unstructured expert interviews. Collecting data from a natural environment for variables as a field study in a non-control setting without interference from individuals; customers, managers, or employees.

\subsection{Theoretical Framework}

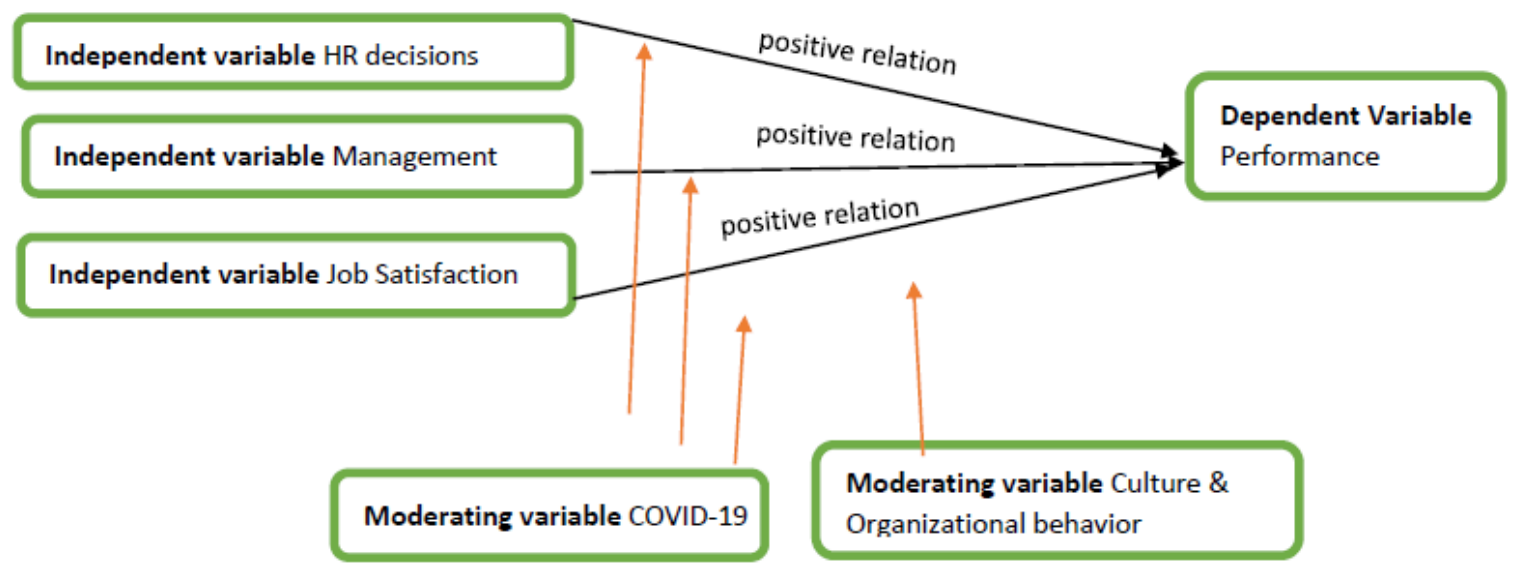

Figure 4. integrated model between the conceptual model and previous model The impact of human resources management on organizational performance (BECKER \& Barry GERHART, August 1996)

After literature review and without finding a suitable model, we can deduct from the several reviews together:

\subsection{Dependent Variable}

Organizational performance is related to human resources especially for services companies as Mwasalat Misr. 


\subsection{Independent Variable}

HR decisions: Performance is positively influenced by the development and the perceived place of human resources in the organization to make the right decisions following an implication in the operations and the strategy of the organization.

Management role: Performance is influenced by leadership and management behavior; research has shown that human resource management actions by business leaders affect business performance and that managers differ in their resource management capabilities which affect business results differently.

Job Satisfaction: Research results from numerous studies suggest the existence of a positive correlation between job satisfaction and individual performance and also address the relationship between job satisfaction and organizational performance (Chan \& Steiner T. L., 2000) (Chandrasekar, 2011) (Ostroff, 1992)

\subsection{Moderating Variable}

Culture \& Organizational behavior: the difference in culture between the employees and the different organizational behaviors has an impact on job satisfaction which par consequences impact the performance (Aguinis, Harry, \& Ryan, 2012)

COVID-19 pandemic: we can deduce a new variable found after the reviews that the COVID-19 has influenced all the variables have an impact on the performance of the company, therefore all the pandemics can change and influence the performance of the organization.

\subsection{Hypotheses/Propositions}

Hypothesis 1: There is a positive relationship between the Good and Adapted HR decisions and the enhancement of company performance.

Hypothesis 2: There is a positive relationship between the effective Management role and the enhancement of company performance.

Hypothesis 3: There is a positive relationship between Job Satisfaction and the enhancement of company performance.

Hypothesis 4: Culture \& Organizational behavior does influence the relation between Job Satisfaction and company performance.

Hypothesis 5: COVID-19 does influence the relation between Job Satisfaction, management role, HR decisions, and company performance.

\subsection{Data Collection}

This paper will use unstructured interviews and questionnaires at stakeholders' approach and will depend on the stakeholder model which shown previously in work published on exploring the impact of corporate social responsibility on organizational performance; the case of Turkish Islamic Banks (Elsafty, Tahon, 2020) and follow the narrative approach, which means making interviews with stakeholders segments and discuss with them about our problem through question and gets answers to face to face, we determined stakeholders segment which has a direct relation with Mwasalat Misr as the management in the company and some of the competitors, customers, and employees. primary data was collected by three methods, the first with unstructured individual interviews with management of public transport companies, the second is phone interviews with employees, and the third way is participant observation and data collection from company databases regarding customers. For the unstructured interview, the topics will be introduced for discussion will be open and allow respondents to talk about their ideas and concerns and their views to investigate the following objectives, covering research variables stated at the theoretical framework:

HR decisions, Management role, Job Satisfaction to help improve company performance and if the Culture \& Organizational behavior, the COVID-19 pandemic does influence company performance, so the researchers used 4 open questions as open-ended questions at each interview: 


\begin{tabular}{|l|l|l|}
\hline Variables & Variable definition & Questions \\
\hline HR decisions & $\begin{array}{l}\text { The importance of HR in any business: that we can measure } \\
\text { performance that often differs significantly between different business } \\
\text { units and different sizes also nature of each organization and the } \\
\text { performance of financial results (BECKER \& Barry GERHART, } \\
\text { August 1996) }\end{array}$ & $\begin{array}{l}\text { How far you can assess human } \\
\text { resource decisions can help } \\
\text { improve business performance? }\end{array}$ \\
\hline $\begin{array}{l}\text { Management } \\
\text { role }\end{array}$ & $\begin{array}{l}\text { Management role: is a continuous process of "identifying. Measuring } \\
\text { and developing the performance of individuals and teams and aligning } \\
\text { performance with the strategic goals of the organization" (Aguinis, } \\
\text { Harry, \& Ryan, 2012). }\end{array}$ & $\begin{array}{l}\text { To what extend you can evaluate } \\
\text { the management roles that can } \\
\text { help enhance the performance of } \\
\text { the company? }\end{array}$ \\
\hline $\begin{array}{l}\text { Job } \\
\text { Satisfaction }\end{array}$ & $\begin{array}{l}\text { It is important to stress that the relationship between job satisfaction } \\
\text { and performance, organizational success is far from simple and } \\
\text { straightforward, Organizational performance is not just individual } \\
\text { performance (Bakotic, 2016) }\end{array}$ & $\begin{array}{l}\text { The } \\
\text { satisfaction and performance? }\end{array}$ \\
\hline COVID-19 & $\begin{array}{l}\text { The influence of the pandemic on the performance Even of all } \\
\text { industries and the Egyptian economy. }\end{array}$ & $\begin{array}{l}\text { what is the influence of Covid 19 } \\
\text { on the number of customers? }\end{array}$ \\
\hline
\end{tabular}

Figure 5. the relationship between Questions \& Variables

Questions will be asked in two different ways by phone with close-ended questions to confirm the relations to a sample of about 37 Drivers in different areas and ages to cover a representative average, this sample size is based on the population of 120 drivers, with a confidence level of $85 \%$ error of $10 \%$. The second way is a face-to-face unstructured interview, with open questions with the 5 biggest Managers of public transport in Cairo so it will be will all 5 persons.

The first interview was with Mwasalat Misr CEO and the answer to the first question concerning the relation between HR decisions and if can help improve the performance the answer was: "undoubtedly HR resources have a real impact on the performance of drivers and all employees but depend on the industry how we can use the functions of human resources, in public transport we believe that the human factor is the engine of the whole industry, that is why we are the first company to have an HR department with all the power needed to improve the performance of all employees" but depend to the industry how we can utilize the functions of the human resources, in public transport we believe that the human factor is the main engine of all the industry that why we enforce the HR roles with all needed power to enhance the performance of all employees. After asking about the manager role, he says "The manager is the leader and he must be chosen carefully because he will influence the whole team, all his decisions will directly influence the performance". About The relationship between job satisfaction and performance? "It is very difficult to have the satisfaction of all the employees, but it is sure that if the employee is satisfied, he will be motivated, and the performance will increase". The influence of Covid 19 on the number of customers? He answers, "without details this situation destroys us; it is against the idea of public transport".

Second interview was with the Commercial Manager and the answer was as follow: "I had seen the company before and after the human resources department, we really increased our performance after the work done and the decisions made by human resources, so I can say that: without a human resources department several companies in our sector have closed, because they did not manage their decision during the period of covid 19 , they did not open again or some of them are trying to cope with a very difficult situation, so HR role is more than important in our company". About managers' role, "manager's decision can increase revenue and a late or no decision can decrease revenue, so the manager is one of, if not the most important reason, to succeed or close a business performance". The relationship between job satisfaction and performance? "people always complain about her situation, so I don't think so". His answers about the influence of Covid 19 was "as previously mentioned we were on the edge of closing the business during this period".

After interview with the chief operating officer and he answers the first question as below: "HR is like the brain of a company without HR the operation cannot function properly, the most important decisions taken by the operation it is made by the HR, the close relationship between these two departments will help to end in the achievement of performance". About the manager role, "The manager is everything, he is the reasons why employees are efficient or not, and if there is a shortage it is always by his responsibility so for sure the manager leads the company to perform". The relation between satisfaction and performance; "Not sure because it is very varied and if we have a relationship it is not significant". The influence of the covid; "the operation it is decreed by the COVID-19 not only of the customers but also of the employees was afraid and some we had a lot of budget to adapt the operation to the new life, so it is about $60 \%$ decrease in the revenues with the curfew especially, and until now we are not as before the COVID-19". 
Then conducted two interviews with the CEO of the biggest competitors in the industry:

For the HR decisions one said "Yes human resources have an important role and its decisions are important but this role the director can do it is not necessary to have a department which costs an additional budget especially in the public transport sector" and other said, "not too many human resources is an additional and unnecessary expense in the public transport sector, a small personnel department is sufficient and the drivers are only looking for money, so with a percentage of income system it motivates them, so the big rhetoric of HR which will only change the culture of this industry, it wastes time and money".

The second question about the management role the answer was the same; "The manager is here to control and follow up to keep performance always high". Then ask them about the relationship between job satisfaction and performance the first answer was "job satisfaction comes with the money they make, so they have to put in the effort and make sure that companies are where they can make a lot of money". The second answers "in public transport, there is no way to have job satisfaction because drivers will never satisfy it is a very difficult job, so money makes them perform". And the last question about the influence of the COVID-19 both confirm "the decrease of the revenues due to the situation".

\subsection{Data Analysis}

After analyzing the data, using content analysis of the outcome of the unstructured interviews then classification using partial descriptive statistical analysis and content analysis on the results of the open-ended questionnaire. Research propositions define the relationship between HR decisions, management and satisfaction has a positive role in changing culture and also increasing performance in service companies and especially in public transport. The study used descriptive research design as the main objective of this research is to determine after reading some recent results on the relations and the effects between 1-the implementation of a different role of human resources system and the importance of all activities relating to employees 2- the influence on the performance of the company of Mwasalat Misr in the field of public transport. 3- the cultural shift of public transport in Cairo.

To be precise gathering, analyzing, and classifying data, I have carefully searched for research articles in the field of human resources that only influence performance. As a part of the management team, the procedure was to ask an indirect question to all levels of employees from top management till the end, observe their productivity using the company tools to see if the performance is increasing. Observe them on the place of work doing the job and the relation between all the variables and the performance. However, the data was analyzed using PBI tools that the company already uses to read performance, is analyzed using mean, standard deviation. Specifically, addressing issues on the roles of human resources on employee performance and by consequences on company performance weighted average and standard deviation were used for self-employed and dependent variables. However, correlation analysis has been used to determine the relationship between the HR Department's role on business performance.

After the stakeholder, the data collected from the database and my observation on clients only show about two points the relationship between HR decisions and performance, and the COVID-19 effect: this shows a real influence on all the measures taken by the direction that reflects customer satisfaction, while customers have declined after COVID-19 and have taken their cars or private taxi.

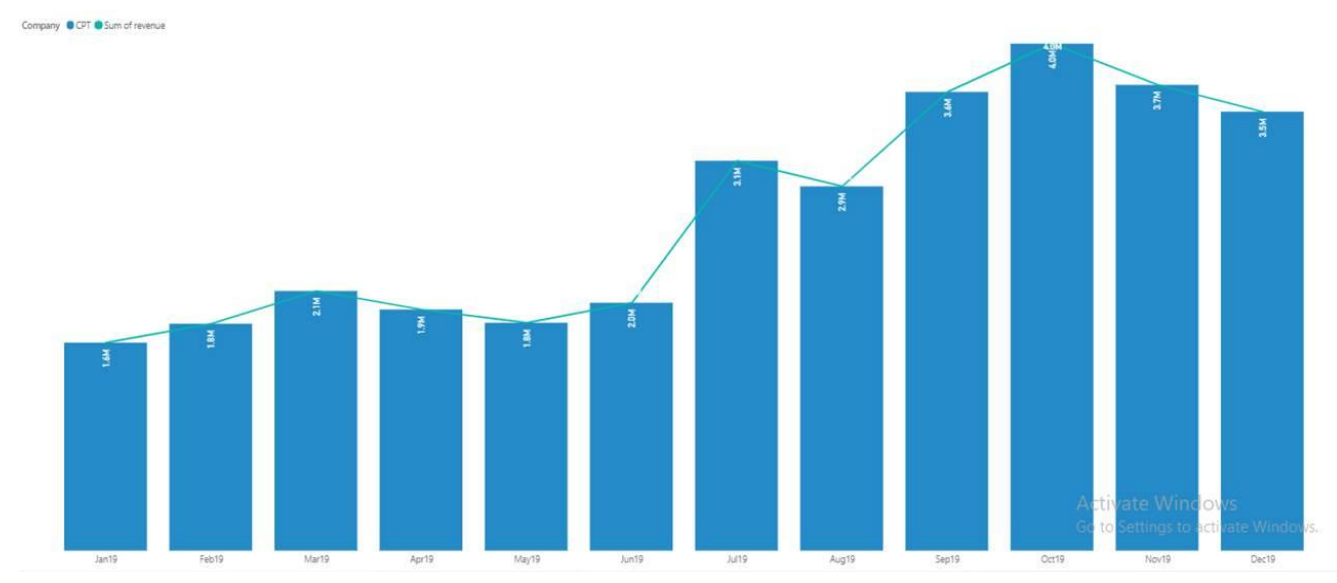

Figure 6. Result of company performance after having an HR department in May 2019, using PBI tools 2019 


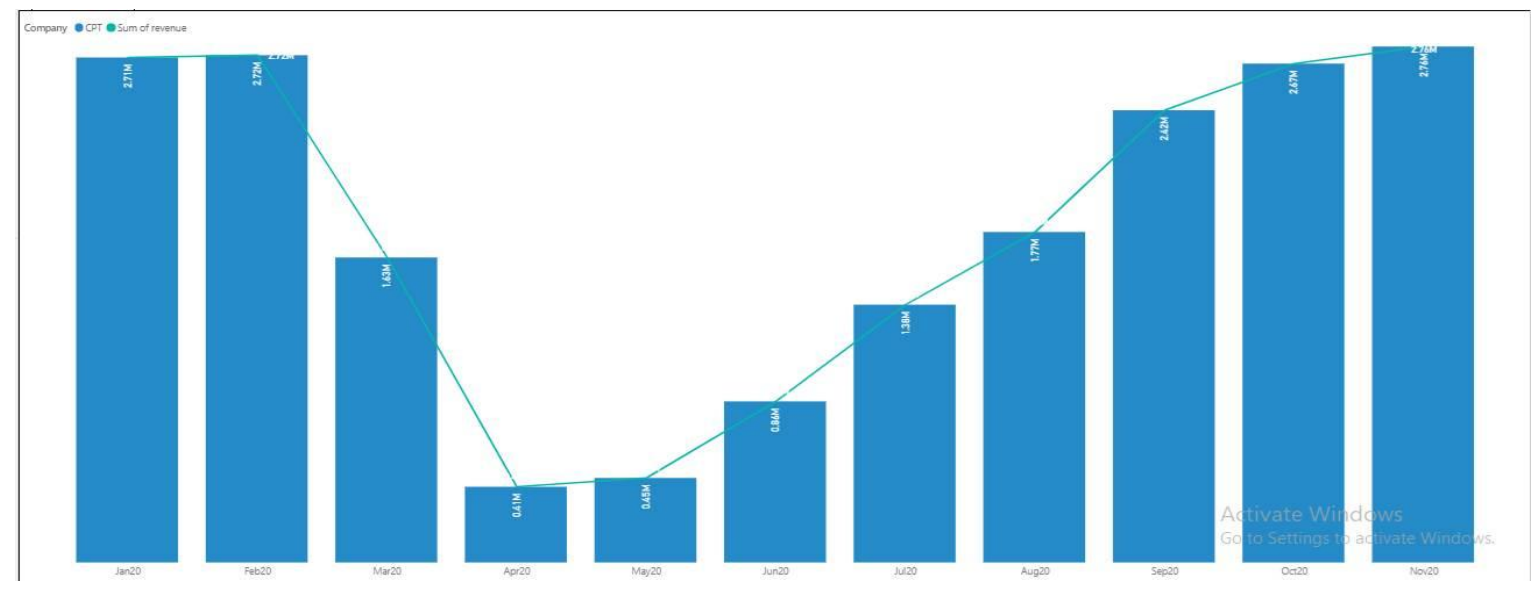

Figure 7. the COVID-19 effect on the company performance using the PBI tools 2020 figures

Results from the survey with the drivers showed that $95 \%$ of drivers strongly agreed that HR decisions affect the company performance, while $60 \%$ only agreed on the relationship between job satisfaction and performance, $98 \%$ Strongly agreed that leadership roles result from increased performance and by the end, $95 \%$ can see the effect of the pandemic on the performance of the organization.

For interviews with management of public transport come from 5 interviews as follows: 4 out of 5 confirm that decisions in terms of human resources can help improve business performance one of these 4 simply says that decisions in terms of human resources can come from of any manager, 5 out of 5 strongly agree on the importance of manager roles, and only 2 confirm the relationship between employee satisfaction and performance while the 5 ensure the negative impact of the pandemic on organizational performance.

Many possible keywords were used to search these results with an independent variable is performance and independent variable of decisions 1-HR 2- Role of management 3- Job satisfaction., resulting in a large number of articles; Newspapers, reports, Business research, however, some of the more relevant studies were ultimately used. Relevant articles were chosen based on some predefined criteria that the articles should: include factual results, recently published, and published in peer-reviewed journals. Finally, some articles were selected then reviewed to find the effects of human resources on organizations. Unfortunately, there were access limitations to many other articles found, which reduced the number of articles available for a more comprehensive review.

\section{Conclusion}

This research explored organizational factors and proposed strategies to improve the performance of Mwasalat Misr company, an Egyptian public transport company with a smart and modern fleet trying to improve the industry culture in Greater Cairo.

Research suggests four factors that influence performance: HR decisions, the role of management, employee satisfaction, and culture \& organizational behaviors.

This research assumes that the public transport industry needs a categorical change in the culture of operation to be able to improve the quality of service and their performance, therefore, HR roles must be more involved in the industry and supported by management and even government. As we can see, this is a mandatory change in this area to succeed in having a reasonable means of transportation that conveys the middle class.

Human resource practices are at the heart of every organization's activity, especially services companies so further research is needed to improve the relationship between the organization's performance and its employees.

The work environment increases employee satisfaction, which influences motivation and behavior, by this way increasing organizational performance.

There is a mutual relationship between the employee and the organization, therefore the employee is rewarded by the organization, then he is satisfied and motivated and feels grateful and suitable for the job, in short, the role of HR; the employee increases the productivity and the performance of the organization.

The covid-19 pandemic has a role of mediating factor between the different variables and the performance. 
The limitations of this research are that it is based only on the observations of the researcher, the comments received from stakeholders, and the analysis of the literature. Another limitation of this research is that it does not address other major factors affecting performance such as political, social, legal, and economic which also influence the business, especially the existence of a regulator to the country.

\section{References}

Aguinis, H., Harry, J., \& Ryan, K. G. (2012). Performance management universals: Think globally and act locally. Bloomington, IN 47405-1701, U.S.A. https://doi.org/10.1016/j.bushor.2012.03.004

Amaratunga, D., \& Baldry, D. (2002). Moving from performance measurement to performance management. https://doi.org/10.1108/02632770210426701

Atkinson, A. (1998). Strategic Performance Measurement and incentive compensation. European Management Journal, 552-561. https://doi.org/10.1016/S0263-2373(98)00032-2

Bakotic, D. (2016). Relation between job satisfaction and organizational performance.

Becker, B., \& Barry, G. (August 1996). The Impact of Human Resources Mgt On Organizational Performance. The Academy of Management Journal, 39(4), 779-801. https://doi.org/10.2307/256712

Chan, K. C., \& Steiner T. L. (2000). Employee Happiness and corporate financial performance.

Chandrasekar, K. (2011). Workplace environment and its impact on organizational performance. International Journal of enterprise computing and business systems, 1, 1-16.

D.Nelson, J., \& Mulley, C. (2003). IATSS Research.

ElSafty, A. (2018). Business Research Methods. Egypt: Lecture Notes, Lecture One.

Elsafty, A. (2020). DrAshrafElsafty Channel. Retrieved from https://www.youtube.com/watch?v=y-jDT2iOOhU\&list=PLKSWZdnzp8p3uFLLh2N8_d0W7ZmJDLMjW \&inde $=42 \& \mathrm{t}=628 \mathrm{~s}$

Elsafty, A., \& AlNawaly, A. (2020). Role of Co-Working Spaces' Services in Entrepreneurs Growth in Upper Egypt, The Case of Step Co-Working Space. Business and Management Studies, 6(2). https://doi.org/10.11114/bms.v6i2.4899

Elsafty, A., Abadir, D., \& Shaarawy, A. (2020). How Does the Entrepreneurs' Financial, Human, Social and Psychological Capitals Impact Entrepreneur'S Success? Business and Management Studies, 6(3), 55-71. https://doi.org/10.11114/bms.v6i3.4980

Elsafty, A., Elbouseery, I., \& Shaarawy, A. (2020). Factors Affecting the Behavioral Intention to Use Standalone Electronic Personal Health Record Applications by Adults in Egypt. Business and Management Studies, 6(4), 14-36. https://doi.org/10.11114/bms.v6i4.5066

Elsafty, A., Elsayed, H., \& Shaaban, I. (2020). A Business Analysis Perspective for Engineering Education in Egypt. Journal of Education and Training Studies, 8(5). https://doi.org/10.11114/jets.v8i5.4721

Elsafty, A., Elsayed, H., \& Shaaban, I. (2020). Educating Engineering Students in Egypt: Recommendations for Improvement. International Journal of Higher Education. https://doi.org/10.5430/ijhe.v9n3p1

Elsafty, A., Elsayed, H., \& Shaaban, I. (2020). Journal of Education and Training Studies, 8(8). https://doi.org/10.11114/jets.v8i8.4901

Elsafty, A., \& Elzeftawy, A. (2021). The New Era of Digital Transformation and COVID-19 Effect on The Employment in Mobile Operators in Egypt. Business and Management Studies, 7(1), 1-21. https://doi.org/10.11114/bms.v7i1.5087

Elsafty, A., \& Ragheb, M. (2020). Role of Human Resource Management towards Employees Retention during Covid-19 Pandemic. Business and Management Studies, 6(2). https://doi.org/10.11114/bms.v6i2.4899

Elsafty, A., \& Tahon, A. (2020). Exploring Impact of Corporate Social Responsibility on Organizational Performance, the Case of Turkish Islamic Banks. Business and Management Studies, 7(1), 1-21. https://doi.org/10.11114/bms.v7i1.5087

Gregorio, M. D., Castro, N. L. J., Lopez-Saez, P., \& Alama-Salazar. (2005). Organizational capital ascompetitive advantage of the firm. Madrid.

Ian Haynes, C. V. (2005). L'expérience australienne. Transport Public International, 24-25.

Jackson, A. E. (2017). what steps employees can take if they disagree or dispute aspects of their review. 
Jalagat, R. (2016). Job Performance, Job Satisfaction, and Motivation. International Journal of Management and Economics, 36-43.

K. A, D. B., \& Heywood, J. S. (2006). Job satisfaction of the highly educated. Scottish Journal of Political Economy, 53, 253-279. https://doi.org/10.1111/j.1467-9485.2006.00379.x

Lebas, M. (1995). Performance measurement and performance management. International journal of production economics, 22-35. https://doi.org/10.1016/0925-5273(95)00081-X

M, A. (2006). A Handbook of Human Resource Management Practice. In A. M, A Handbook of Human Resource Management Practice (p. 264). London: Kogan Page.

Motowidlo, S., \& Kell, H. (2012). Industrial and Organizational Psychology.

Mullins, J. (2005). Management and organizational behavior.

Ostroff, C. (1992). The relationship between satisfaction, attitudes, and performance: An Organizational Level Analysis. Journal of Applied Psychology, 77, 963-974. https://doi.org/10.1037/0021-9010.77.6.963

Owais, L. (2020). The effects of using Performance measurement systems on organizations' performance. Cross-Cultural Management Journal, 111-121.

\section{Copyrights}

Copyright for this article is retained by the author(s), with first publication rights granted to the journal.

This is an open-access article distributed under the terms and conditions of the Creative Commons Attribution license (http://creativecommons.org/licenses/by/4.0/). 